\title{
REVIEWS
}

\section{Review of the Clinical Characteristics of Coronavirus Disease 2019 (COVID-19)}

\author{
Fang Jiang ${ }^{7}$, Liehua Deng ${ }^{2}$, Liangqing Zhang ${ }^{3}$, Yin Cai ${ }^{7}$, Chi Wai Cheung ${ }^{7}$, and \\ Zhengyuan Xia ${ }^{7,3}$
}

\begin{abstract}
'Department of Anesthesiology, Li Ka Shing Faculty of Medicine, The University of Hong Kong, Hong Kong, SAR, China; ${ }^{2}$ Department of Critical Care Medicine, Affiliated Hospital of Guangdong Medical University, Zhanjiang, China; ${ }^{3}$ Department of Anesthesiology, Affiliated Hospital of Guangdong Medical University, Zhanjiang, China.
\end{abstract}

In late December 2019, a cluster of cases with 2019 Novel Coronavirus pneumonia (SARS-CoV-2) in Wuhan, China, aroused worldwide concern. Previous studies have reported epidemiological and clinical characteristics of coronavirus disease 2019 (COVID-19). The purpose of this brief review is to summarize those published studies as of late February 2020 on the clinical features, symptoms, complications, and treatments of COVID-19 and help provide guidance for frontline medical staff in the clinical management of this outbreak.

KEY WORDS: COVID-19; SARS-CoV-2; coronavirus; pneumonia; Wuhan; review.

J Gen Intern Med 35(5): 1545-9

DOI: $10.1007 / \mathrm{s} 11606-020-05762-\mathrm{w}$

(c) Society of General Internal Medicine 2020

\section{INTRODUCTION}

In December 31, 2019, hospitals reported a cluster of cases with pneumonia of unknown cause in Wuhan, Hubei, China, attracting great attention nationally and worldwide. ${ }^{1}$ On January 1,2020, Wuhan public health authorities shut down the Huanan Seafood Wholesale Market, where wild and live animals were sold, due to a suspected link with the outbreak. On January 7, 2020, researchers rapidly isolated a novel coronavirus (SARS-CoV-2, also referred to as 2019-nCoV) from confirmed infected pneumonia patients. Real-time reverse transcription polymerase chain reaction (RT-PCR) and next-generation sequencing were used to characterize it. ${ }^{2}$ On January 23, 2020, owing to the large flow of people during the Chinese Spring Festival, public transport was suspended in Wuhan and, eventually, in all the cities in Hubei Province to reduce the risk of further transmission.

The number of RT-PCR-confirmed cases has increased rapidly. On January 30, 2020, the World Health Organization (WHO) declared COVID-19 (as it would be officially known as of February 11) to be a Public Health Emergency of International Concern (PHEIC) and declared an epidemic. As of February 24, 2020, 80,239 cases were confirmed worldwide

Received February 24, 2020

Revised February 26, 2020

Accepted February 27, 2020

Published online March 4, 2020 causing 2700 deaths. Mainland China, and especially Hubei Province, has borne the brunt of the epidemic, reporting 77,780 cases. Outside of mainland China, 33 countries have reported 2549 confirmed infections and 34 fatalities. $^{3}$

We reviewed the published clinical features, symptoms, complications, and treatments of patients with COVID-19 to help health workers around the world combat the current outbreak.

We searched PubMed for all published articles regarding COVID-19 up to February 19, 2020. Keywords used were "COVID-19," "2019 novel coronavirus," "SARS-CoV-2," "2019-nCoV," "Wuhan coronavirus," and "Wuhan seafood market pneumonia virus." After careful screening, six published articles with confirmed cases were identified and included in this review. The summary of included clinical studies is shown in Table 1.

\section{NATURAL HISTORY AND CLINICAL CHARACTERISTICS}

Huang et al. ${ }^{4}$ first reported clinical features of 41 patients confirmed to be infected with COVID-19 on January 2, 2020, which include 13 ICU cases and 28 non-ICU cases. More than half of the cases (66\%) had been exposed to the Huanan Seafood Wholesale Market. Almost all the patients had bilateral lung ground glass opacity on computed tomography imaging. The initial symptoms included fever (98\%), cough (76\%), dyspnea (55\%), myalgia or fatigue (44\%), sputum production (28\%), headache (8\%), hemoptysis (5\%), and diarrhea $(3 \%)$. Only one patient did not present fever in the early stage of disease. Twelve (29\%) cases progressed to acute respiratory distress syndrome (ARDS), 5 (12\%) had acute cardiac injury, 3 (7\%) had acute kidney injury (AKI), and 3 $(7 \%)$ had shock. At the data cutoff date, $28(68 \%)$ patients were discharged and $6(15 \%)$ had died.

On January 20, 2020, Chen et al. ${ }^{5}$ reported 99 cases with SARS-CoV-2-infected pneumonia. This case series revealed that older males with comorbidities as a result of weaker immune function were the most susceptible to COVID-19 incidence. The symptoms, complications, and treatments in this study were similar to the previous published study by Huang and colleagues. ${ }^{4}$ At the data cutoff date, 31 (31\%) were discharged and $11(11 \%)$ died, and $57(58 \%)$ of the patients 


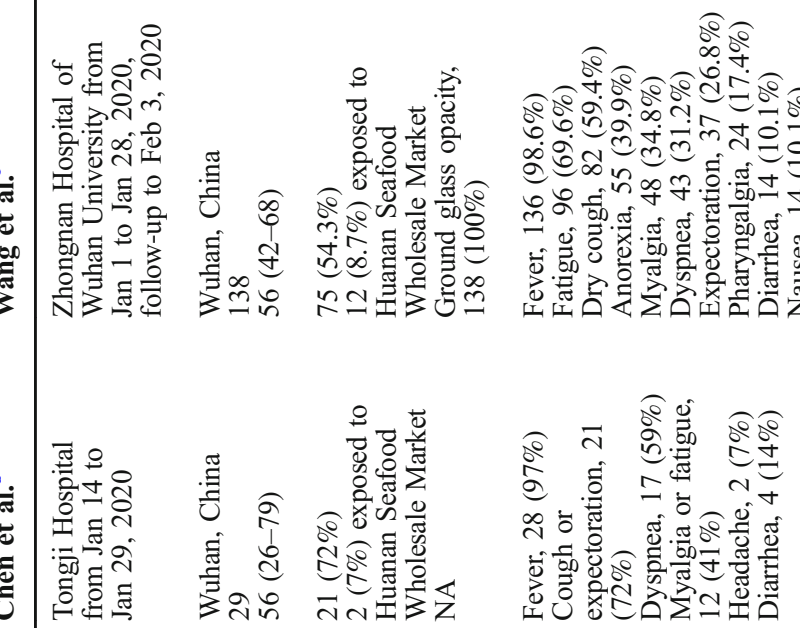

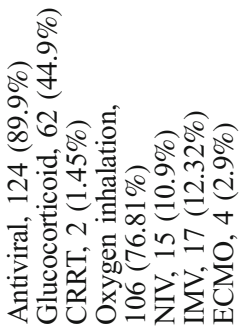

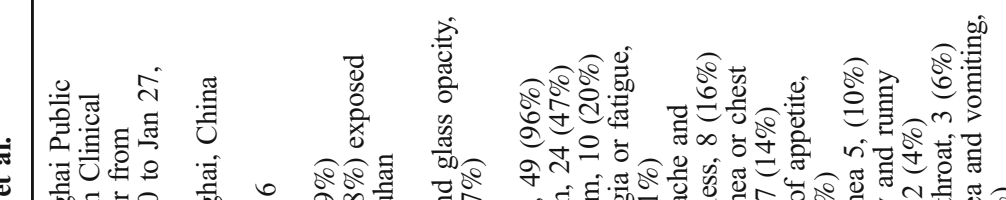

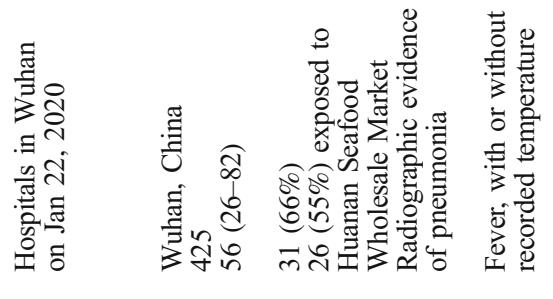

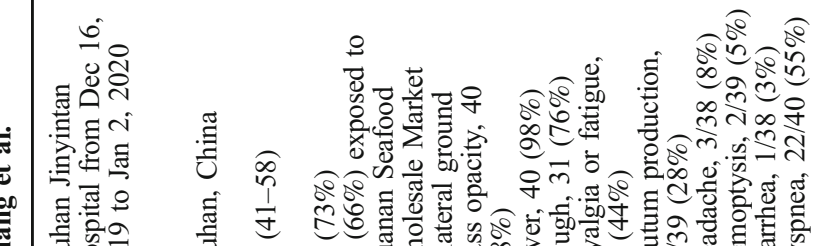

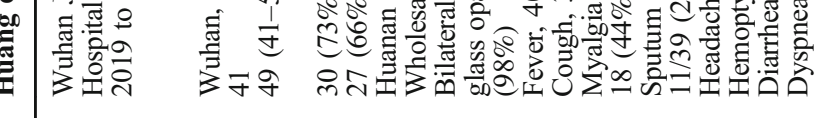

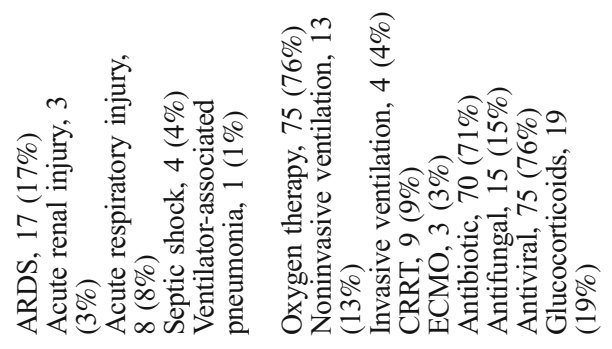

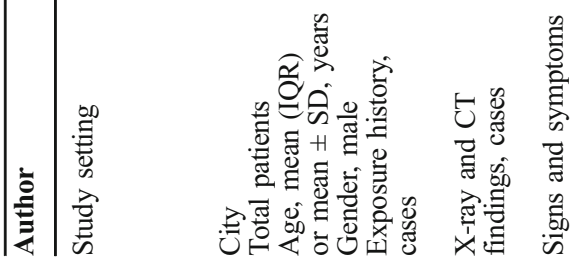


were still hospitalized. A study of Li et al. ${ }^{6}$ reported on 425 COVID-19 cases in Wuhan confirmed between January 1 and 22,2020 . The mean incubation period was 5.2 days, with the 95th percentile of the distribution at 12.5 days, though uncertainty remains.

Two subsequent studies confirmed the pattern of signs and symptoms. ${ }^{7,} 8$ At the time of this writing, the most recent published case series ${ }^{9}$ of 138 confirmed cases included 36 requiring intensive care by the data cutoff date of February 3,2020 . It also found the common presenting symptoms of fever $(136,99 \%)$, fatigue $(96,70 \%)$, and dry cough $(82,59 \%)$, though there were two patients who did not present any signs of fever at the onset of illness. A higher proportion of cases presented with gastrointestinal symptoms including diarrhea and nausea $(14,10 \%)$ than in previous series. Forty-seven (34\%) were discharged while 6 (4\%) died, while the remainder were still hospitalized. The organ failure complications were similar to the original studies.

Taken together, these studies indicate the main clinical manifestations of COVID-19 are fever (90\% or more), cough (around 75\%), and dyspnea (up to 50\%). A small but significant subset has gastrointestinal symptoms. Preliminary estimates of case fatality, likely to fall as better early diagnostic efforts come into play, is about $2 \%$, mostly due to ARDS, $\mathrm{AKI}$, and myocardial injury.

\section{BASIC VIROLOGY}

Coronaviruses are widespread in humans and several other vertebrates and cause respiratory, enteric, hepatic, and neurologic diseases. Notably, the severe acute respiratory syndrome coronavirus (SARS-CoV) in 2003 and Middle East respiratory syndrome coronavirus (MERS-CoV) in 2012 have caused human epidemics. Comparison with the current virus shows several significant differences and similarities. Both MERS$\mathrm{CoV}$ and SARS-CoV have much higher case fatality rates (40\% and $10 \%$, respectively). Though the current SARS$\mathrm{CoV}-2$ shares $79 \%$ of its genome with SARS-CoV, it appears to be much more transmissible. ${ }^{10}$

Both SARS-CoVs enter the cell via the angiotensinconverting enzyme 2 (ACE2) receptor. ${ }^{11,12}$ The SARS-Cov2 first predominantly infects lower airways and binds to ACE2 on alveolar epithelial cells. Both viruses are potent inducers of inflammatory cytokines. The "cytokine storm" or "cytokine cascade" is the postulated mechanism for organ damage. The virus activates immune cells and induces the secretion of inflammatory cytokines and chemokines into pulmonary vascular endothelial cells.

\section{TRANSMISSION DYNAMICS AND PROTECTIVE MEASURES}

The preliminary estimate of R 0 (the expected number of cases directly produced by one person in a population susceptible to 
infection) for COVID-19 is 2.2 (95\% CI, 1.4 to 3.9). ${ }^{6}$ Fomites are suspected as the main source of infectious particles, though some uncertainty remains. Other coronaviruses have been shown to persist for days on uncleaned surfaces. ${ }^{10}$ Additionally, SARS-CoV-2 RNA was detected in the stool specimen in a person who had symptoms while the serum specimen tested negative. ${ }^{13}$ Recently, SARS-Cov-2 was isolated from a swab sample of a confirmed patient's feces by Chinese researchers,${ }^{14}$ indicating the potential for fecal-oral transmission. Studies have shown effective person-to-person transmission of 2019-nCoV even in the presence of isolation efforts in medical facilities. ${ }^{15,16} \mathrm{~A}$ case series of nine infected pregnant women did not reveal evidence of third trimester vertical transmission after cesarian section. ${ }^{17}$ Transmission in health settings is a very serious threat. The most recent case series reported $57(41 \%)$ of 138 patients were infected hospital settings, including 40 (29\%) medical staff. ${ }^{9}$ While further study is needed, it appears that asymptomatic persons are also potential sources of 2019-nCoV infection. ${ }^{18,19}$

Handwashing is the mainstay of viral control. Contact isolation gear such as masks, gowns, and gloves are also recommended. Transmission via ocular surface is possible ${ }^{20}$ so eye protection should also be used.

\section{VACCINES AND TREATMENTS}

Several efforts to develop vaccines are underway, but the WHO estimates it will take 18 months for the COVID-19 vaccines to be available. ${ }^{21}$ At present, most treatment is symptomatic and supportive, though anti-inflammatory and antiviral treatments have been employed. Supportive treatment for complicated patients has included continuous renal replacement therapy (CRRT), invasive mechanical ventilation, and even extracorporeal membrane oxygenation (ECMO). No specific antiviral drugs have been confirmed effective. The first reported patient with 2019-nCoV infection in the USA was treated with remdesivir, ${ }^{13}$ and others have used antiretrovirals like ritonavir, with trials of both in progress. ${ }^{22}$ A recent study conducted by the "front-line" health care providers combating COVID-19 in Wuhan indicated that systemic corticosteroid treatment did not show significant benefit. ${ }^{23}$ Baricitinib has been suggested as a potential drug for the treatment in the hope that it might reduce the process of both virus invasion and inflammation. ${ }^{24}$

\section{CONCLUSION}

Despite some diversity in initial symptoms, most COVID-19 patients have fever and respiratory symptoms. For now, travel history to epidemic areas is important to the diagnosis and should be obtained on all patients with flu-like syndromes. If positive, timely referral to the public health authorities for testing is crucial. Frontline medical staff are at risk and should employ protective measures. Treatment is mainly supportive and symptomatic, though trials of vaccines and antivirals are underway. Healthcare providers should follow subsequent reports as the situation will likely change rapidly.

Corresponding Author: Zhengyuan Xia, Department of Anesthesiology, Li Ka Shing Faculty of Medicine, The University of Hong Kong, Hong Kong, SAR, China (e-mail: zyxia@hku.hk).

Authors' Contributions F. J. and Z. X. planned the work. F. J. drafted the manuscript. Z. X. revised the manuscript. L. D., L. Z., Y. C., and C. W. C. participated in the literature search and discussion. All authors read and approved the final manuscript. Editor's note: Several of the authors are natives of Hubei Province.

Funding Information The authors' work was supported by the National Natural Science Foundation of China (NSFC, 81970247).

\section{Compliance with Ethical Standards:}

Conflict of Interest: The authors declare that they do not have a conflict of interest.

\section{REFERENCES}

1. Wang C, Horby PW, Hayden FG, Gao GF. A novel coronavirus outbreak of global health concern. Lancet. 2020 Jan 24. pii: S0140-6736(20)30185-9. https://doi.org/10.1016/S0140-6736(20)30185-9. [Epub ahead of print]

2. Zhu N, Zhang $\mathbf{D}$, Wang $\mathbf{W}$, et al. A novel coronavirus from patients with pneumonia in China, 2019. N Engl J Med. 2020. https://doi.org/10. 1056/NEJMoa2001017. [Epub ahead of print]

3. World Health Organization. Coronavirus disease 2019 (COVID-19) Situation Report-36. https://www.who.int/emergencies/diseases/novel-coronavirus-2019/situation-reports/. Updated 2020. Accessed February 25, 2020.

4. Huang $\mathbf{C}$, Wang $\mathbf{Y}, \mathbf{L i} \mathbf{X}$, et al. Clinical features of patients infected with 2019 novel coronavirus in Wuhan, China. Lancet. 2020; pii: S01406736(20)30183-5. https://doi.org/10.1016/S0140-6736(20)30183-5. [Epub ahead of print]

5. Chen N, Zhou M, Dong $\mathbf{X}$, et al. Epidemiological and clinical characteristics of 99 cases of 2019 novel coronavirus pneumonia in Wuhan, China: a descriptive study. Lancet. 2020; pii: S0140-6736(20)30211-7. https:// doi.org/10.1016/S0140-6736(20)30211-7. [Epub ahead of print]

6. Li Q, Guan $\mathbf{X}$, Wu P, et al. Early Transmission Dynamics in Wuhan, China, of Novel Coronavirus-Infected Pneumonia. N Engl J Med. 2020; https://doi.org/10.1056/NEJMoa2001316. [Epub ahead of print]

7. Song F, Shi N, Shan F, et al. Emerging Coronavirus 2019-nCoV Pneumonia. Radiology. 2020; 6:200274. https://doi.org/10.1148/ radiol.2020200274. [Epub ahead of print]

8. Chen L, Liu HG, Liu W, et al. Analysis of clinical features of 29 patients with 2019 novel coronavirus pneumonia. Zhonghua Jie He He Hu Xi Za Zhi. 2020;43(0):E005. https://doi.org/10.3760/cma.j.issn.1001-0939. 2020.0005. [Epub ahead of print]

9. Wang D, Hu B, Hu C, et al. Clinical Characteristics of 138 Hospitalized Patients With 2019 Novel Coronavirus-Infected Pneumonia in Wuhan, China. JAMA. 2020. https://doi.org/10.1001/jama.2020.1585. [Epub ahead of print]

10. de Wit E, van Doremalen N, Falzarano D, Munster VJ. SARS and MERS: recent insights into emerging coronaviruses. Nat Rev Microbiol. 2016; 14(8):523-34. https://doi.org/10.1038/nrmicro.2016.81.

11. Zhou P, Yang XL, Wang XG, et al. A pneumonia outbreak associated with a new coronavirus of probable bat origin. Nature. 2020; https://doi.org/ 10.1038/s41586-020-2012-7. [Epub ahead of print]

12. Wan Y, Shang J, Graham R, Baric RS, Li F. Receptor recognition by novel coronavirus from Wuhan: An analysis based on decade-long structural studies of SARS. J Virol. 2020; pii: JVI.00127-20. https:// doi.org/10.1128/JVI.00127-20. [Epub ahead of print]

13. Holshue ML, DeBolt C, Lindquist S, et al. First case of 2019 novel coronavirus in the United States. N Engl J Med 2020; published online Jan 31. https://doi.org/10.1056/NEJMoa2001191.

14. Huaxia. Chinese researchers isolate novel coronavirus strain from feces. 2020. Xinhuanet, Feb 13, 2020. http://www.xinhuanet.com/english/ 2020-02/13/c_138780710.htm 
15. Phan LT, Nguyen TV, Luong $\mathbf{Q C}$, et al. Importation and human-to-human transmission of a novel coronavirus in Vietnam. N Engl J Med 2020; published online Jan 28. https://doi.org/10.1056/NEJMc2001272.

16. Chan JF, Yuan S, Kok KH, et al. A familial cluster of pneumonia associated with the 2019 novel coronavirus indicating person-to-person transmission: a study of a family cluster. Lancet 2020; published online Jan 24. 10.1016/S0140-6736(20)30154-9.

17. Chen $\mathbf{H}$, Guo $\mathbf{J}$, Wan $\mathbf{C}$, et al. Clinical characteristics and intrauterine vertical transmission potential of COVID-19 infection in nine pregnant women: a retrospective review of medical records. https://doi.org/10. 1016/S0140-6736(20)30360-3.

18. Rothe C, Schunk M, Sothmann P, et al. Transmission of 2019-nCoV Infection from an Asymptomatic Contact in Germany. N Engl J Med. 2020; https://doi.org/10.1056/NEJMc2001468. [Epub ahead of print]

19. Hoehl S, Rabenau H, Berger A, et al. Evidence of SARS-CoV-2 Infection in Returning Travelers from Wuhan, China. New England Journal of Medicine. 2020. https://doi.org/10.1056/NEJMc2001899. [Epub ahead of print]

20. Lu CW, Liu XF, Jia ZF. 2019-nCoV transmission through the ocular surface must not be ignored. Lancet. 2020; pii: S0140-
6736(20)30313-5. https://doi.org/10.1016/S0140-6736(20)303135. [Epub ahead of print]

21. Huaxia. WHO says vaccines against novel coronavirus 18 months away, pushes global research. 2020. Xinhuanet, Feb 12, 2020. http://www. xinhuanet.com/english/2020-02/12/c_138777886.htm.

22. A randomized, open-label, blank-controlled trial for the efficacy and safety of lopinavir-ritonavir and interferon-alpha $2 \mathrm{~b}$ in hospitalization patients with novel coronavirus infection. Available from www.chictr.org. cn/showprojen.aspx?proj=48684. Accessed February 24, 2020.

23. Kui L, Fang YY, Deng $\mathbf{Y}$, et al. Clinical characteristics of nove coronavirus cases in tertiary hospitals in Hubei Province. Chin Med J (Engl). 2020. https://doi.org/10.1097/CM9.0000000000000744. [Epub ahead of print]

24. Richardson $\mathbf{P}$, Griffin I, Tucker $\mathbf{C}$, et al. Baricitinib as potential treatment for 2019-nCoV acute respiratory disease. Lancet. 2020 Feb 4 pii: S0140-6736(20)30304-4. https://doi.org/10.1016/S0140-6736(20) 30304-4. [Epub ahead of print]

Publisher's Note: Springer Nature remains neutral with regard to jurisdictional claims in published maps and institutional affiliations. 